\title{
Modelling of Heat Exchangers with Computational Fluid Dynamics
}

\author{
Chamil Abeykoon \\ Aerospace Research Institute and Northwest Composites Centre, Department of Materials, Faculty of Science and \\ Engineering, The University of Manchester, Oxford Road, M13 9PL, Manchester, UK \\ Email: chamil.abeykoon@manchester.ac.uk
}

\begin{abstract}
Heat transfer is one of the major aspects of machineries, devices and industrial processes for maintaining their functionality and also for achieving better product quality. Hence, different types of heat exchangers are used in these applications with the purpose of removal of extra process/device heat to maintain them in desirable working temperatures. However, the size of a heat exchanger is a key consideration for any type of process or device as it decides the size of the machine/device or of the processing plant. This study aims to study the design of a heat exchanger theoretically and then to use computational fluid dynamics to optimize its performance. For design purposes, a counter flow heat exchanger was considered and its length was calculated with the LMTD method while the pressure drop and energy consumption were also calculated with the Kern method. Then, a computational model of the same heat exchanger was developed with ANSYS and then this was extended to six different models by changing its parameters for the optimization purposes. Also, these models were used to analyse the heat transfer behaviour, mass flow rates, pressures drops, and flow vortices of the shell and tube flows inside the heat exchanger. Theoretical and CFD results showed only a $1.05 \%$ difference in terms of the cooling performance of the hot fluid. The axial pressure drop showed positive correlations with both the overall heat transfer coefficient and pumping power. Overall, CFD modelling gave a promising outlook for design and optimization of heat exchangers.
\end{abstract}

Keywords: Shell-and-tube heat exchanger, Heat transfer enhancement, Fluid flow modelling, CFD, Optimization

\section{Introduction}

Heat transfer can be occurred via three main modes: conduction, convection (free or forced), and radiation. Also, heat transfer can be promoted by artificial approaches while it also occurs naturally from or to a thermodynamic system due to buoyancy forces. Moreover, heat transfer occurs between all live and inanimate things. Hence, heat transfer is one of the most important phenomena in our lives and also in most of the modern machineries, devices and processes. It is obvious that various types of heat exchangers are widely used in many applications to add or remove the heat [1,2]. They can be classified based on their flow arrangement (parallel flow, counter flow, cross flow), construction (shell-and-tube, plate, plate-fin, shell and plate, adiabatic wheel), surface compactness or the number of fluids in use [3-5]. Heat exchangers allow exchanging heat between two or more media (metals, water, oil, air, etc) for heating and cooling purposes. Currently, various forms of heat exchanging are used in the practical applications such as refrigeration, air conditioning, automobiles, process industry, solar water heater units, thermal power plants, and so forth. For all of these applications, the required size of a heat exchanger should be determined based on the amount of heat load to be added or removed from a system at a given time. Obviously, the size of a heat exchanger is crucial for any application as it is a key factor of deciding the physical size of a component or the space requirements of an industrial process. Hence, numerous research works are underway to enhance the heat transfer in heat exchangers and hence to replace bulky heat exchangers (conventional designs) with advanced compact designs, with the aid of modern computer-based design and optimization tools, which can be beneficial in various ways [6-10]. Heat transfer performance of heat exchangers can be enhanced by active, passive or compound techniques [11]. Many of the previous research [12-18] have focused on passive techniques possibly due to the fact that they do not demand extra energy. Meantime, compound methods or systems use two or more active or passive techniques to improve the rate of heat transfer. In current industry, it is rudimentary for companies to have cost-efficient heat exchangers with a view on the operational costs, but also the costs of developing and materials have to be as low as possible. Nowadays, the focus is on optimising heat exchanger design with a view on keeping the pressure drop as low as possible, while retaining the heat transfer coefficient as high as possible. Previous studies [19-37] showed a number of different approaches to enhance the performance of a heat exchanger via design and optimization. The coherences between the pressure drop and the heat transfer coefficient are a key in optimising a heat exchanger design. Decreasing the pressure drop affects the operating costs positively due to the decrease in required pumping power. By increasing the heat transfer 
coefficient, the capital costs of a heat exchanger can be decreased with the possible reduction of the required length and material, and hence a less possible complexity in maintenance. But usually, the heat transfer enhancement options (e.g., optimized tube bank, decreasing the baffle cut ratio and baffle spacing,) influence the pressure drop negatively.

\subsection{Shell-and-Tube Heat Exchanger}

This study is focused on modelling of a shell-and-tube heat exchanger since it is the most commonly used type in industry [38]. Mukherjee [39] claims that nowadays the design of shell-and-tube heat exchangers is mainly carried-out with the help of computational software packages. However, to use such software packages, it is necessary to understand the fundamental principles of heat exchanger design and its main components (e.g., shell, shell cover, tubes, channel, channel cover, tube sheet, baffles, etc). The basic arrangement of a fixed-tube sheet shell-and-tube heat exchanger is shown in Section 3 [40] and this type has straight tubes where the stationary tube sheets at both ends are welded to the shell to secure the tubes. Also, this is an economical option given its simple construction and the cheapest shell-and-tube heat exchanger type. Also, it can be easily dismantled and repaired, hence can be easily cleaned. The Logarithmic Mean Temperature Difference (LMTD) method $[1-5,41]$ is one of the widely used methods to determine the rate of heat transfer within a heat exchanger which assumes a constant wall temperature along the heat exchanger and considers a logarithmic average based on the temperature difference of the cold and hot fluid streams at the each end of the heat exchanger. Instead, the Number of Transfer Units (NTU) method can also be applied for calculating the rate of heat transfer if the inlet temperatures of both fluid streams are known [1-5, 41]. According to this method, heat transfer rate of a heat exchanger of infinite length can be determined as one of the fluids would achieve the maximum potential temperature difference.

\subsection{Previous Optimization Studies with PSO and GA}

Nowadays, the design optimization of equipment via techniques such as genetic algorithm (GA), particle swarm optimization (PSO) and simulated annealing (SA) has become more and more popular and applied. Liu et al. [19] describes how to optimize the design of a heat exchanger on the basis of constructal theory [42]. In this method, a heat exchanger is segmented into several parts and by adjusting the parameters via a GA and then each part of the heat exchanger is optimised concurrently. Such optimization work should help to improve the hydraulic efficiency and cost factors and also to decrease the irreversible power losses as effectively as achievable. The results showed that the costs compared to the original design were reduced. Work by Amidpour et al. [20], a method was proposed with the same constructal theory to decrease the total costs by improving the overall heat transfer coefficient with regard to the tube diameters. Furthermore, some other works have performed optimization case studies with GA codes. Hajabdollahi et al. [21] designed a heat exchanger with the NTU method and optimised via a GA with the objectives of maximizing the effectiveness and reducing the total costs. The results showed that the design parameters like tube pitch ratio, tube length, tube number and baffle spacing ratio caused some problems between the two objectives. Generally, with these types of optimisation, an increase in the total cost is possible with the increase of effectiveness and hence multi-objective optimisation approaches should be applied for optimal shell-and-tube heat exchanger designs. Patel et al. [22] used a PSO to enhance the heat transfer coefficient of a shell-and-tube heat exchanger by increasing the fluid velocities. The PSO results showed better performance than a GA approach for the same application (hence a cost reduction). Benetto et al. [23] claimed that although the heat transfer coefficients are higher with turbulent flow conditions, laminar flows are desirable when it is required to decrease the pressure drop. Fukai et al. [24] claimed that the best possible ways for improving the overall heat transfer coefficient are either by increasing the heat transfer surface area or by the refinement of the heat transfer coefficient. They enhanced the heat transfer coefficient significantly by using a sheet-fin mechanism via increasing heat transfer surface area of a heat exchanger. Particularly this method is suitable for tube bank arrangements with long pitches.

\subsection{Previous Optimization Studies with CFD Approaches}

With the current development of computational technologies, CFD approaches are also emerging in design optimization. As was stated by Ahmad et al. [43], both LMTD and NTU methods demonstrate some deficiencies and hence the designs made by these methods needs to have a physical prototype to test their performance. Thus, CFD approaches should be really attractive for testing of the performance of any number of new designs without fabricating prototypes. 
CFD software packages employ governing equations to solve the cells numerically in terms of the pressure distribution, temperature parameters, flow behaviour/rates, etc. Furthermore, CFD approaches can be used with any heat exchanger type. From a wide array of turbulence models, the $K-\varepsilon$ model is the mostly used model in CFD for heat exchanger design. Bock et al. [27] performed 3-D numerical simulations for a shell-and-tube heat exchanger with rod-baffles using four different models: a unit model, a periodic model, a porous model and a whole model. Of these models, the unit model had the lowest performance in heat transfer enhancement. The porous and whole models demonstrated high precision in predicting the pressure drop while unit and periodic models were unable to directly predict the hydraulic performance. The whole model showed the highest precision of all methods but it demanded high performance computing as this model has the largest number of cells among four models. Ozden et al. [26] tested a shell-and-tube heat exchanger using two CFD turbulence flow models ( $K-\varepsilon$, Sparlat-Allmaras). Particularly the effects of baffle cut ratio, number of baffles, baffle spacing and shell diameter towards the heat transfer coefficient and the pressure drop were studied. Their CFD results are in agreement with the Bell-Delaware method with regard to the heat transfer coefficient [44]. Hence, the use of CFD approaches together with supporting experiments should be an effective approach to achieve fast results in heat exchanger design. Some of the vital factors for the performance of a heat exchanger are the baffle design, baffle spacing and the baffle cut ratio and hence the proper implementation of these in CFD platforms are also really important for accurate results.

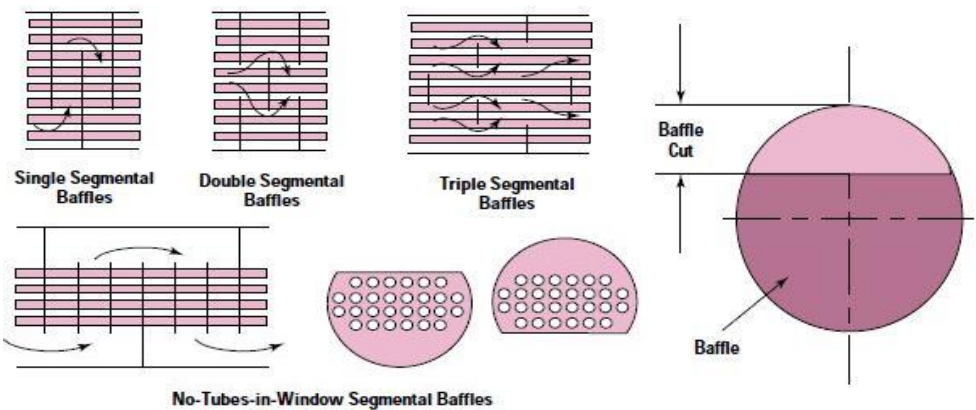

Fig. 1: Different types of segmental baffles and rod baffles [39]

For this study, plate and rod baffles are considered and some of the current common baffle types are shown in Fig. 1. Mainly, baffles are used to direct the flow of the shell side fluid and also to reduce the effects of vibration to the tube bundle. Also, baffles create a cross flow velocity component which increases the heat transfer coefficient. The baffle spacing is the offset between two adjacent baffles in the same side of the shell (top or bottom) and is a very critical parameter in shell-and-tube heat exchanger design which should be chosen appropriately [39]. Liu et al. [28] stated that heat exchangers with segmental baffles are the most applied shell-and-tube type. However, due to the possible disadvantages such as high pumping power, fouling in the dead zones, and no sufficient prevention of vibrations, it is necessary to come-up with advanced/improved designs to avoid or narrow these limitations. In terms of the design aspects, this study aims mainly to explore the effects of baffle cut ratio and the number of tubes towards the performance of a shelland-tube heat exchanger. Further, six CFD models will be used in design optimization by analysing the pressures drops, flow temperatures, mass flow rates, flow velocities and vortices of the shell and tube fluid flows inside the heat exchanger.

\section{Methodology}

Here, a specific heat transfer question was selected and at first it was solved theoretically with the Logarithmic Mean Temperature Difference (LMTD) method. Then, the same model was implemented on a CFD platform (ANSYS) and the CFD model was validated with theoretical information. Then, it was used for an optimization study by changing the design parameters but considering the same heat transfer load. Altogether six different CFD models were developed and more details will be given in the following sections.

\section{Details of the Case Study}

The design considered in this work is a fixed-tube sheet shell-and-tube heat exchanger as it is the most common type used in practice. It has a tube bundle with straight tubes and a tube bank arrangement in staggered design to increase the 


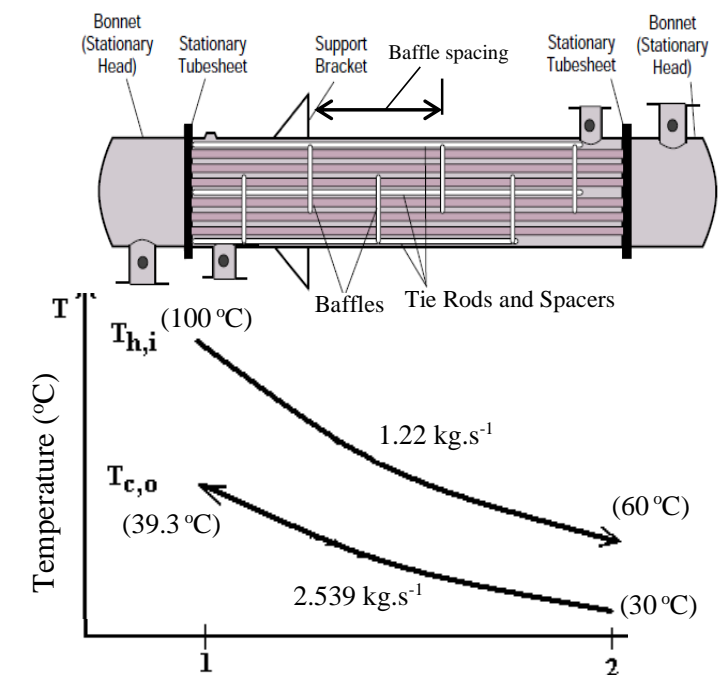

Fig. 2: The arrangement of the heat exchanger (top) [39] and the T-x diagram of the prosed case study (bottom) heat transfer coefficient as shown in Fig. 2. Baffles are installed to cause turbulence and cross flow velocity components to increase the convection coefficient of the shell side fluid, the working fluids enter at the opposite ends (i.e., a counter flow) of the heat exchanger. Thus, combined effects of cross and counter flow arrangements occur in this heat exchanger design. The installed baffles also prevent deflection to the tube bundle and effects of vibration caused by the shell side fluid stream. The tube sheets are welded to the shell body and also secure the tubes. The case study considered was to cool down a hot fluid at $100{ }^{\circ} \mathrm{C}$ to $60{ }^{\circ} \mathrm{C}$ by transferring the heat load to a counter flowing cold fluid. Water was taken as both the hot and cold fluids and the hot fluid was set inside the tubes while the cold fluid was flowing across the outer surfaces of the tubes inside the shell. The required length of the heat exchanger was theoretically determined by considering all related factors (listed in Tables 1 and 2) together with the resulting axial pressure drop and total pumping power demand. The arrangement of the heat exchanger and the corresponding $\mathrm{T}-x$ diagram with some key parameters are shown in Fig. 2.

\section{Computational Fluid Dynamics (CFD) Design}

In this study, the same theoretical design was implemented on the CFD software platform ANSYS Workbench 15.0. Altogether 6 different arrangements (6 CFD models) of a heat exchanger (HE) were implemented with CFD and tested, and their key design information together with the theoretical calculation details is given below in Tables 1 and 2 (definition of all the terms presented in these tables can be found in the nomenclature at the end of the paper).

Table 1: Design Specifications of each model

\begin{tabular}{|lc|ccccccc|}
\hline Parameter & Unit & $\begin{array}{c}\text { Theoretical } \\
\text { calculation }\end{array}$ & CFD HE 20 & CFD HE 30 & $\begin{array}{c}\text { CFD HE 12 } \\
\text { tubes }\end{array}$ & $\begin{array}{c}\text { CFD HE 20 } \\
\text { tubes }\end{array}$ & $\begin{array}{c}\text { CFD HE 24 } \\
\text { baffles }\end{array}$ & $\begin{array}{c}\text { CFD HE 26 } \\
\text { baffles }\end{array}$ \\
\hline$D_{\text {tube }}$ & {$[\mathrm{m}]$} & 0.02 & 0.02 & 0.02 & 0.02 & 0.02 & 0.02 & 0.02 \\
$D_{\text {shell }}$ & {$[\mathrm{m}]$} & 0.18 & 0.18 & 0.18 & 0.18 & 0.18 & 0.18 & 0.18 \\
$D_{\text {inletshell }}[\mathrm{m}]$ & 0.0508 & 0.0508 & 0.0508 & 0.0508 & 0.0508 & 0.0508 & 0.0508 \\
$S_{L}$ & {$[\mathrm{~m}]$} & 0.03 & 0.03 & 0.03 & 0.03 & 0.03 & 0.03 & 0.03 \\
$S_{T}$ & {$[\mathrm{~m}]$} & 0.03 & 0.03 & 0.03 & 0.03 & 0.03 & 0.03 & 0.03 \\
$S_{D}$ & {$[\mathrm{~m}]$} & 0.03354 & 0.03354 & 0.03354 & 0.03354 & 0.03354 & 0.03354 & 0.03354 \\
$B F$ & {$[\mathrm{~m}]$} & 0.12 & 0.12 & 0.12 & 0.12 & 0.12 & 0.1223 & 0.113 \\
$A_{\text {flow }}$ & {$\left[\mathrm{m}^{2}\right]$} & 0.0216 & 0.0216 & 0.0216 & 0.0216 & 0.0216 & 0.022 & 0.0201 \\
$D_{H}$ & {$[\mathrm{~m}]$} & 0.02 & 0.02 & 0.02 & 0.02 & 0.02 & 0.02 & 0.02 \\
$N$ & - & 16 & 16 & 16 & 12 & 20 & 16 & 16 \\
$m$ & - & 25 & 25 & 25 & 25 & 25 & 24 & 26 \\
$L$ & {$[\mathrm{~m}]$} & 3.12 & 3.12 & 3.12 & 3.12 & 3.12 & 3.12 & 3.12 \\
$C_{\text {tube }}$ & {$[\mathrm{m}]$} & 0.01 & 0.01 & 0.01 & 0.01 & 0.01 & 0.01 & 0.01 \\
Baffle cut & {$[\%]$} & - & 20 & 30 & 30 & 30 & 30 & 30 \\
\hline
\end{tabular}

CFD HE 20: no. of tubes - 16, no. of baffles - 25, baffle cut ratio - 20\% CFD HE 30: no. of tubes - 16, no. of baffles - 25, baffle cut ratio - $30 \%$ CFD HE 12 tubes: no. of tubes - 12, no. of baffles - 25, baffle cut ratio - $30 \%$ CFD HE 20 tubes: no. of tubes - 20, no. of baffles - 25, baffle cut ratio - 30\% CFD HE 24 baffles: no. of tubes - 16, no. of baffles - 24, baffle cut ratio - $30 \%$ CFD HE 26 baffles: no. of tubes - 16, no. of baffles - 26, baffle cut ratio - 30\%
Table 2: Thermodynamic and fluid flow specifications

\begin{tabular}{|c|c|c|c|c|c|c|c|c|}
\hline Parameter & Unit & $\begin{array}{l}\text { Theoretical } \\
\text { calculation }\end{array}$ & CFD HE 20 & CFD HE 30 & $\begin{array}{c}\text { CFD HE } 12 \\
\text { tubes }\end{array}$ & $\begin{array}{l}\text { CFD HE } 20 \\
\text { tubes }\end{array}$ & $\begin{array}{c}\text { CFD HE } 24 \\
\text { baffles }\end{array}$ & $\begin{array}{c}\text { CFD HE } 26 \\
\text { baffles }\end{array}$ \\
\hline$\rho_{h}$ & $\left.\mathrm{~kg} / \mathrm{m}^{3}\right]$ & 971.8 & 971.8 & 971.8 & 971.8 & 971.8 & 971.8 & 971.8 \\
\hline$\rho_{c}$ & $\left.\mathrm{~kg} / \mathrm{m}^{3}\right]$ & 995.7 & 995.7 & 995.7 & 995.7 & 995.7 & 995.7 & 995.7 \\
\hline$v_{\text {inlet, shell }}$ & {$[\mathrm{m} / \mathrm{s}]$} & 1.25812 & 1.25812 & 1.25812 & 1.25812 & 1.25812 & 1.25812 & 1.25812 \\
\hline$v_{\text {tube }}$ & {$[\mathrm{m} / \mathrm{s}]$} & 0.25 & 0.25 & 0.25 & 0.333 & 0.2 & 0.25 & 0.25 \\
\hline$\dot{m}_{h}$ & {$[\mathrm{~kg} / \mathrm{s}]$} & 1.22 & 1.219 & 1.219 & 1.217 & 1.216 & 1.219 & 1.218 \\
\hline$\dot{m}_{c}$ & {$[\mathrm{~kg} / \mathrm{s}]$} & 2.539 & 2.465 & 2.465 & 2.464 & 2.463 & 2.467 & 2.467 \\
\hline$q$ & {$[W]$} & 204814 & - & - & - & - & - & - \\
\hline$\Delta T_{l m}$ & {$\left[{ }^{\circ} \mathrm{C}\right]$} & 49.59 & - & - & - & - & - & - \\
\hline$T_{c, 0}$ & {$\left[{ }^{\circ} \mathrm{C}\right]$} & 39.3 & 42.43 & 39.85 & 35.54 & 40.78 & 40.49 & 39.34 \\
\hline$T_{h, o}$ & {$\left[{ }^{\circ} \mathrm{C}\right]$} & 60 & 54.09 & 59.27 & 67.77 & 57.67 & 58.24 & 58.3 \\
\hline$R e_{s}$ & - & 8983.76 & - & - & - & - & - & - \\
\hline$R e_{t}$ & - & 13680.81 & - & - & - & - & - & - \\
\hline$\overline{N u}_{s}$ & - & 135.51 & - & - & - & - & - & - \\
\hline$\overline{N u}_{t}$ & - & 59.5 & - & - & - & - & - & - \\
\hline$h_{\text {shell }}$ & $\mathrm{V} / \mathrm{m}^{2} \mathrm{~K}$ & 4410.85 & - & - & - & - & - & - \\
\hline$h_{\text {tube }}$ & $\mathrm{V} / \mathrm{m}^{2} \mathrm{~K}$ & 1993.28 & - & - & - & - & - & - \\
\hline$U$ & $\mathrm{v} / \mathrm{m}^{2} \mathrm{~K}$ & 1372.87 & - & - & - & - & - & - \\
\hline$\Delta P_{\text {shell }}$ & {$[\mathrm{Pa}]$} & 10161.98 & 21650.94 & 9977.85 & 8593.63 & 11300.09 & 10059.58 & 10894.59 \\
\hline$\Delta P_{\text {tube }}$ & {$[\mathrm{Pa}]$} & 136.819 & 174.195 & 148.26 & 234.458 & 115.341 & 225.449 & 174.774 \\
\hline$P$ & {$[W]$} & 37.26 & 76.88 & 35.55 & 30.81 & 40.13 & 36.01 & 38.88 \\
\hline
\end{tabular}

Here, CFD HE 30 model is the equivalent of the theoretical design and a schematic of the CFD HE 30 model (with 16 staggered tubes) with its mesh is shown in Fig. 3. In each CFD model, 53 and 26 locations were marked to measure the interested parameters in shell and tube side flows, respectively, and these points related to CFD HE 30 model are shown in Fig. 4. The $1^{\text {st }}$ and $2^{\text {nd }}$ models (CFD HE 20 and CFD HE 30) were used mainly to investigate the effects of different baffle cut ratios. The other four models were implemented with the same baffle cut ratio $(30 \%)$ but with varying the number of tubes and baffles by maintaining a constant mass flow rate, to analyse the changes in parameters such as pressure drops, fluid outlet temperature, and velocity distributions. Eventually, the most suitable design will be selected with respect to the required outlet temperature of the hot fluid and the axial pressure drop of the shell-and-tube heat exchanger. 


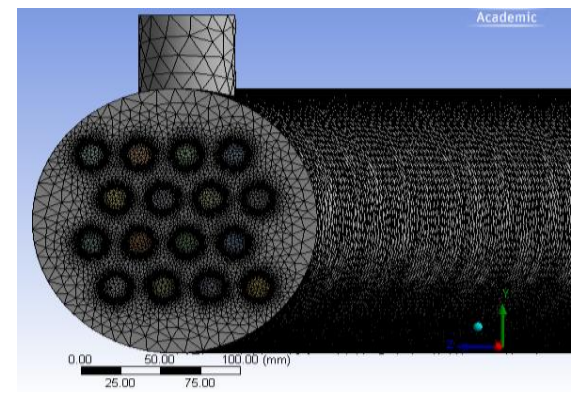

Fig. 3: CFD HE 30 design (with 16 tubes) with the generated mesh

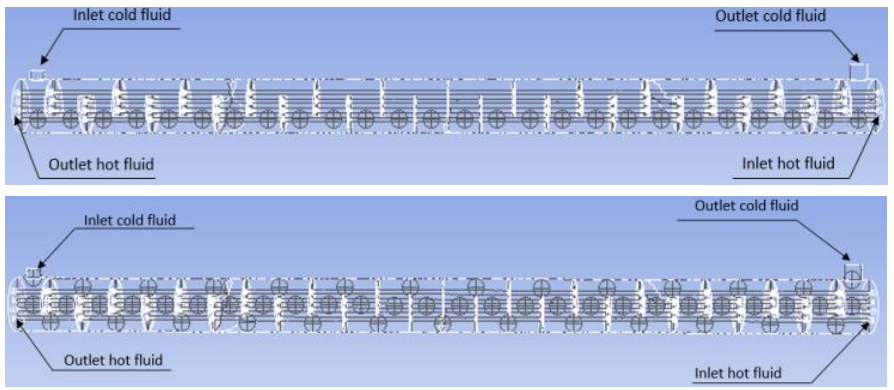

Fig. 4: Interested locations for parameter measurements for HE 30- tube side fluid (top), shell side fluid (bottom)

\section{Results and Discussion}

For all the CFD models, the axial temperature profiles showed a quite linear increase for the shell side fluid flow (cold fluid) and a decrease for the tube flow (hot fluid) as was expected. However, the nature of the flow vortices were dependent upon the factors such as the flow velocity, baffle cut ratio, number of baffles and tubes, etc. The nature of the flow vortices for CFD HE 30 is shown in Fig. 5. As it is evident, the fluid flow velocity increases as passes the baffles. Vortexes are noticeable to the left side of each baffle. This type of a turbulent/mixing flow is promising for heat transfer enhancement but detrimental in terms of the pressure drop and hence with the pumping power demand as well.

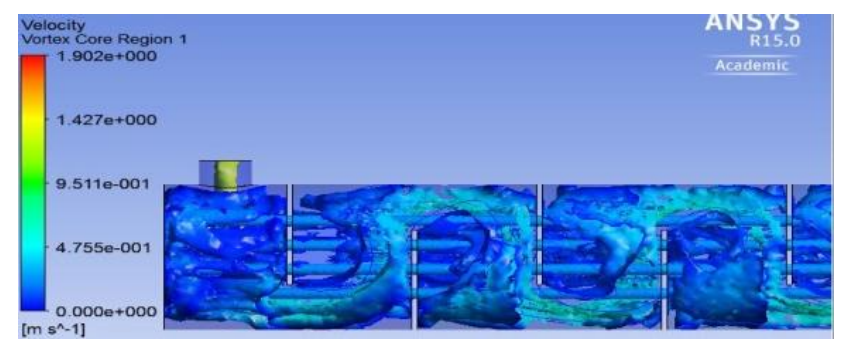

Fig. 5: Fluid flow behaviour inside the shell of the heat exchanger: HE 30 model

By comparing both HE 20 and HE 30 models (the only difference of these two models is the baffle cut ratio), the shell side fluid velocity and pressure drop increase with the increase of baffle cut ratio from $30 \%$ to $20 \%$. Owing to the increased vortex regions, HE 20 shows better heat transfer performance (sees Fig. 6) but with a higher pressure drop (see Fig. 7) and hence it shows an increase in pumping power as well (see Table 2). Hence, this fact agrees with the claim made by Mukherjee [39], that finding of the right balance between the baffle cut ratio and baffle spacing is a key aspect of a well-optimized heat exchanger design in terms of thermal, constructional and energy aspects.

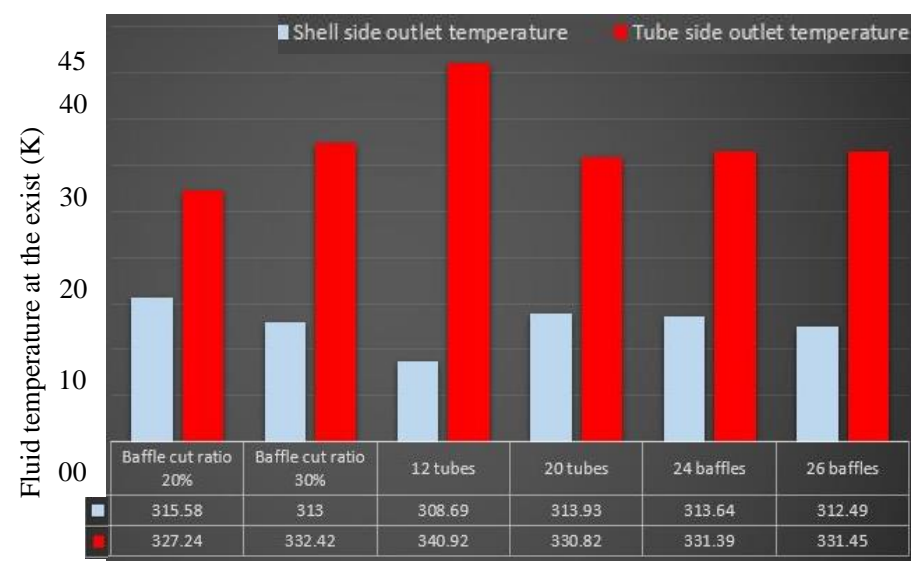

Fig. 6: Fluid flow outlet temperatures in shell and tube sides for 6 CFD models tested 
The main purpose of the case study considered in this work is to cool down a hot fluid to $60{ }^{\circ} \mathrm{C}(333 \mathrm{~K})$ at the outlet. Here, all six CFD models considered heat exchangers with the same length and four of them are quite ok in achieving this expected output temperature where CFD HE 30 is the best, as shown in Fig. 6. Hence, it can be assumed that the chosen baffle spacing as well as the number of tubes in CFD HE 30 model provides the best combination to achieve the desired outcomes from the heat exchanger. Furthermore, this proves the accuracy of the theoretical calculations performed for the required outlet temperatures with the LMTD method. As the number of tubes decreased from 16 to 12 (CFD HE 12 tubes), the outlet temperature of the hot fluid is too high than the desired which might be due to the high fluid flow velocity that should be required to maintain the desired mass flow rate. The shell and tube sides' axial pressure drops of all 6 CFD models were evaluated and details are given in Fig. 7. The highest pressure drop $(21.65 \mathrm{kPa})$ occurs in the heat exchanger with a baffle cut ratio of $20 \%$ (CFD HE 20) where its pressure drop is almost the double compared to other five models. All the other five models are with a baffle cut ratio of $30 \%$ and among them the one with 20 tubes (CFD HE 20 tubes) marked the highest pressure drop $(11.3 \mathrm{kPa})$. Obviously, the shell side pressure drop is always high mostly due to the complicated baffle placements and tubes. As it is clear from Fig. 7, the heat exchanger design with 12 tubes (the lowest tube number of all designs) shows the lowest pressure drop inside the shell (also demanded the highest inlet velocity) which can be appreciated. Furthermore, increase of the number of baffles has also caused to increase the pressure drop. The highest tube side pressure drop occurs in the HE model with 12 tubes and this is due to the demand of high inlet velocity to main the mass flow rate. The heat exchanger with 20 tubes demands the lowest fluid flow velocity and hence the smallest tube side pressure drop.

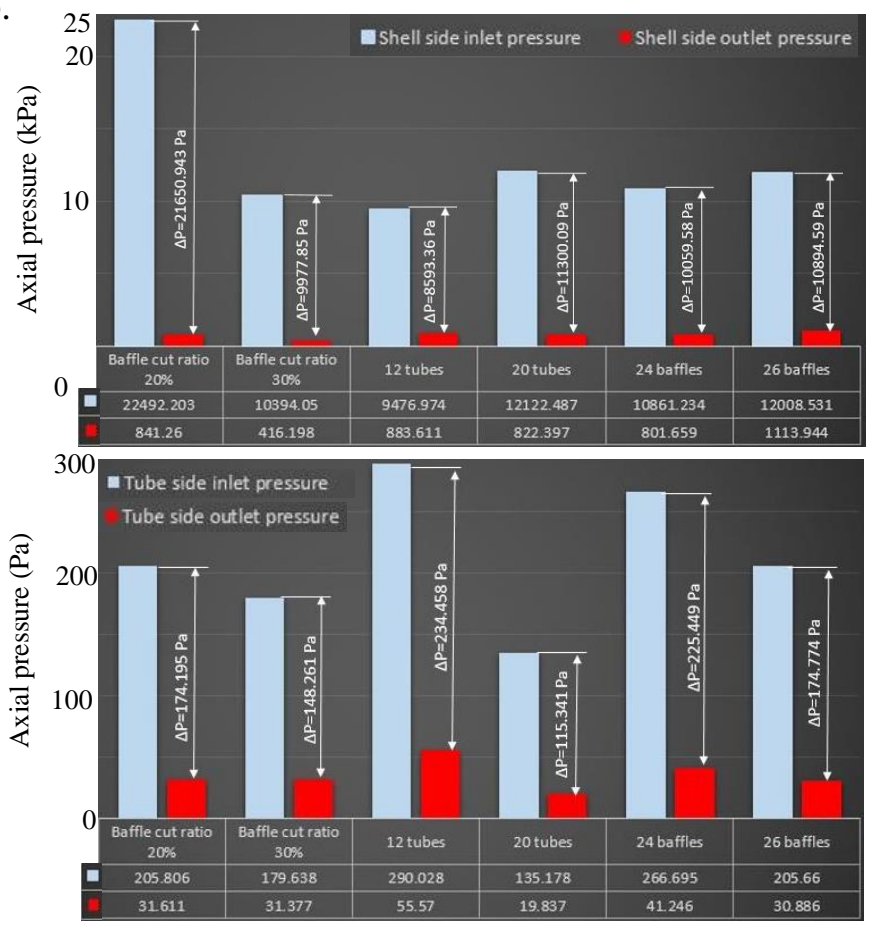

Fig. 7: Axial pressure drops of 6 CFD models: shell (top), tubes (bottom)

Overall, of the six designs, CFD HE 30 shows the most favourable results in terms of the expected outcomes and the energy demand. In addition to the six models discussed in this paper, there are some other possible ways to alter the thermodynamic parameters, such as the use of different flow arrangements or a tube-bank. The impact of changing vital design parameters is obvious from the results of the six CFD models tested. Obviously, the correct combination of baffle spacing and baffle cut ratio is a key to the HE performance. As was realized from the CFD models, decrease of baffle cut ratio below $30 \%$ will greatly influence the pressure drop and the required outlet temperature and this is in agreement with the findings/climes made previously [19-37]. Based on both CFD modelling and theoretical calculations, it showed that $30 \%$ baffle cut ratio is the most efficient and hence five CFD models were implemented with $30 \%$ baffle cut ratio and then 
they were used to analyse the effect of other parameters such as the number of tubes and baffles. Theoretically, the desired hot fluid exit temperature was $60{ }^{\circ} \mathrm{C}$ and this was achieved as $59.27^{\circ} \mathrm{C}$ with CFD HE 30 model. The percentage mismatch of exit hot temperature (theoretical to CFD) is as small as $1.05 \%$. Moreover, as was mentioned, CFD HE 30 model was able to achieve a lower pressure drop compared to CFD HE 20 model. For the CFD HE 30, the pressure drops in shell and tube sides were $9978 \mathrm{~Pa}$ and $148 \mathrm{~Pa}$, respectively. The corresponding theoretical values were $10162 \mathrm{~Pa}$ and $137 \mathrm{~Pa}$, respectively. Here, the percentage mismatches of pressure drops (theoretical to CFD) for shell and tube sides are $1.81 \%$ and $-8.03 \%$, respectively. These differences in theoretical and CFD results should mostly be due to the assumptions attributed with the theoretical calculations. For example, in the theoretical calculations, it was assumed that there is no heat loss to the surroundings. But in the CFD simulation this assumption does not appear as ANSYS can easily calculate the heat loss to the surroundings. Furthermore, the accuracy of the CFD results depends on the nature/quality of the mesh development as well. Hence, in this study, a detailed investigation was made on the effect of the size, type and the number mesh elements on the accuracy of the results prior to implementing final six CFD models. Generally, the result of this work confirms that the theoretical and CFD results are in good agreement.

\section{Conclusions}

Obviously, a sound knowledge in thermodynamics, fluid dynamics and CFD is crucial for the design and optimization of a compact heat exchanger. In this work, six CFD models were developed and the accuracy of these was validated by a detailed theoretical calculation. Based on the CFD results, it was recognized that the careful selection of parameters such as the baffle cut ratio, number of baffles and tubes, flow and tube arrangements are vital in optimizing the performance of a shell-and-tube heat exchanger for a given heat load. Of the six CFD models tested, CFD HE 30 model (with 30\% baffle cut ratio, 16 tubes and 25 baffles) gave the best performance for the given task and this is well aligned with the theoretical results as well. A decrease in baffle cut ratio increases the heat transfer coefficient in shell side but this also causes to increase the pressure drop. Obviously, the number of tubes inside a heat exchanger has an influence on tube flow velocity to main the required mass flow rate, where the lower the number of tubes the higher the pressure drop for a given task. More importantly, findings of this work are in agreement with the previously reported research and this proves the accuracy of the findings made. In terms of achieving the desired hot fluid exit temperature, the theoretical and CFD results showed a mismatch of only around $1.05 \%$. For the pressure drops in shell and tube sides, these mismatches were $1.81 \%$ and $-8.03 \%$, respectively. Overall, the results of this work confirm that the CFD modelling is promising for design and optimization of a heat exchanger. In future work, it is recommended to identify the effects of tube material (such as replacing steel with copper) and dimensions (diameter and thickness) on the optimization particularly to achieve a more compact design. The component failure modes should also be tested to optimize their dimensions and this should help to achieve the best compact heat exchanger design with an optimal thermal efficiency.

\section{Nomenclature}

\section{Symbol - Description}

$A_{\text {flow }}-$ Cross flow area of the tube bank

$B F-$ Baffle spacing

$C_{\text {tube }}-$ Clearance between tubes

$D_{\mathrm{H}}$ - Hydraulic diameter

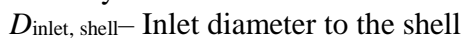

$D_{\text {shell, }} D_{\text {tube }}$ - Diameters of the shell and tube

$h_{\text {shell }}, h_{\text {tube }}-$ Heat transfer coefficients in shell and tube sides

$L$ - Length of the tubes

$m$ - Number of baffles inside the shell

$\dot{m}_{h}, \dot{m}_{c}$ - Mass flow rates of the hot and cold fluids

$N$ - Number of tubes inside the shell

$\overline{N u}_{s}, \overline{N u}_{t}$ - Nusselt number in shell and tube side fluids

Unit
$\left[\mathrm{m}^{2}\right]$
$[\mathrm{m}]$
$[\mathrm{m}]$
$[\mathrm{m}]$
$[\mathrm{m}]$
$[\mathrm{m}]$
$\left[\mathrm{W} \cdot \mathrm{m}^{-2} \cdot \mathrm{K}\right]$
$[\mathrm{m}]$
$[-]$
$\left[\mathrm{kg} \cdot \mathrm{s}^{-1}\right]$
$[-]$
$[-]$

Symbol - Description

$P$ - Total power consumption

$q-$ Heat load

Reynols number in shell and tube side fluids $[-]$

$S_{\mathrm{L}}-$ Longitudinal pitch

$S_{\mathrm{T}}-$ Transverse pitch

$S_{\mathrm{D}}-$ Diagonal pitch

$T_{\mathrm{h}, \mathrm{o}}, T_{\mathrm{c}, \mathrm{o}}-$ Outlet temperature of hot and cold fluids

$U$ - Overall heat transfer coefficient

$v_{\text {inlet,shell }}$ - Inlet velocity of shell side fluid

$v_{\text {tube }}-$ Velocity of tube side fluid

$\Delta T_{\mathrm{lm}}$ - Log mean temperature difference

$\Delta P_{\text {shell, }} \Delta P_{\text {tube }}-$ Pressure drop in shell and tube sides

$\rho \mathrm{h}, \rho_{\mathrm{c}}-$ Density of hot and cold fluids
Unit

[W]

$\mathrm{W}]$

[m]

[m]

[m]

$\left[{ }^{\circ} \mathrm{C}\right]$

$\left[\mathrm{W} \cdot \mathrm{m}^{-2} \cdot \mathrm{K}\right]$

$\left[\mathrm{m} \cdot \mathrm{s}^{-1}\right]$

$\left[\mathrm{m} \cdot \mathrm{s}^{-1}\right]$

$\left[{ }^{\circ} \mathrm{C}\right]$

$[\mathrm{Pa}]$

[kg. $\left.\mathrm{m}^{-3}\right]$ 


\section{References}

[1] Y. Cengel, Introduction to Thermodynamics and Heat Transfer, McGraw-Hill Education; 2 Ed, 2010.

[2] N. V. Suryanarayana, Engineering Heat Transfer, West Publishing Company, USA, 1995.

[3] F. P. Incropera, D. P. DeWitt, T. L. Bergman, A. S Lavine, Fundamentals of Heat and Mass Transfer, Wiley, USA, 2006.

[4] F. M. White, Heat and Mass Transfer, Addison-Wesley Publishing Company, USA, 1991.

[5] T. D Eastop and A. McConkey, Applied Thermodynamics for Engineering Applications, Longman Publishers, Singapore, 1993.

[6] A. Dewan, P. Mahanta, K. S. Raju and P. S. Kumar, Review of passive heat transfer augmentation techniques, Proc. Inst. Mech. Eng. Part A J. Power Energy, 218 (7), 509-527, 2004.

[7] A. Gupta and M. Uniyal, Review of heat transfer augmentation through different passive intensifier methods, IOSR J. of Mechanical and Civil Engineering, 1 (4), 14-21, 2012.

[8] N. K. Nagayach, A. B. Agrawal, Review of heat transfer augmentation in circular and non-circular tube, Int. J. Eng. Res. App., 2 (5), 796-802, 2012.

[9] A. B. Ganorkar and V. M. Kriplani, Review of heat transfer enhancement in different types of extended surfaces, Int. J. Eng. Sci. Techno., 3 (4), 3304-3313, 2011.

[10] K. Stone and S. P. Vanka, Review of Literature on Heat Transfer Enhancement in Compact Heat Exchangers, Available at: https://ideals.illinois.edu/bitstream/handle/2142/11540/TR105.pdf?sequence=2, A report prepared by University of Illinois, August 1996.

[11] C. Abeykoon, Improving the Performance of Shell-and-Tube Heat Exchangers by the Addition of Swirl, Int. J. of Process Syst. Eng., 2 (3), 221-245, 2014.

[12] S. Eiamsa-ard and P. Promvonge, Enhancement of heat transfer in a tube with regularly-spaced helical tape swirl generators, Sol. energy, 78 (4), 483-484, 2005.

[13] R. M. Manglik and A. E. Bergles, Heat transfer and pressure drop correlations for twisted-tape inserts in isothermal tubes, Part I. Laminar flows, ASME J. of Heat Transfer, 115 (4), 881-889, 1993.

[14] R. M. Manglik and A. E. Bergles, Heat transfer and pressure drop correlations for twisted-tape inserts in isothermal tubes: Part II-Transition and turbulent flows. ASME J. of Heat Transfer, 115 (4), 890-896, 1993.

[15] S. W. Hong and A. E. Bergles, Augmentation of laminar flow heat transfer in tubes by means of twisted-tape inserts, ASME J. of Heat Transfer, 98 (2), 251-256, 1976.

[16] S. Eiamsa-ard, C. Thianpong and P. Promvonge, Experimental investigations of heat transfer and pressure drop characteristics of flow through circular tube fitted with regularly-spaced twisted tape, The Joint Int. Conf. on Sustainable Energy and Environment, Thailand, pp 18-22, 2004.

[17] F. Chang and V. K. Dhir, Mechanisms of heat transfer enhancement and slow decay of swirl in tubes using tangential injection, Int. J. Heat Fluid Flow, 16 (2), 78-87, 1995.

[18] C. Yildiz, Y. Bicer and D. Pehlivan, Influence of fluid rotation on the heat transfer and pressure drop in double pipe heat exchangers. Appl. Energy, 54 (1), 49-56, 1996.

[19] W. Liu, S. R. Oh, J. Yang, Optimization of shell-and-tube heat exchangers using a general design approach motivated by constructal theory, Int. J. Heat Mass Transfer, 77, 1144-1154, 2014.

[20] M. Amidpour, A.V. Azad, Economic optimization of shell and tube heat exchanger based on constructal theory, Energy, 36 (2011) 1087-1096

[21] H. Hajabdollahi and S. Sanaye, Multi-objective optimization of shell and tube heat exchangers, Appl. Therm. Eng. ,30 (2010) 1937-1945

[22] V. K. Patel and R.V. Rao, Design optimization of shell-and-tube heat exchanger using particle swarm optimization technique, Appl. Therm. Eng., 30, 1417-1425, 2010.

[23] D. Di Benetto, S. Montelpare, R. Ricci, R. Romagnoli, Convective heat transfer increase in internal laminar flow using a vibrating surface, Int. J. Therm. Sci., 84, 358-368, 2014. 
[24] J. Fukai, H. Mitani, K. Nakaso, Convection heat transfer in a shell and tube heat exchanger using sheet fins for effective utilization of energy, Int. J. Heat Mass Transfer, 82, 581-587, 2015.

[25] A.S. Wilson, M.K. Bassiouny, Modeling of heat transfer for flow across tube banks, Chem. Eng. Process., 39, 1-14, 2000.

[26] E. Ozden, I. Tari, Shell side CFD analysis of a small shell-and-tube heat exchanger, Energy Convers. Manage, 51, 1004-1014, 2010.

[27] J. Bock, A.M. Jacobi, W. Liu, L. Ma, J. Yang, A comparison of four numerical modelling approaches for enhanced shell-and-tube heat exchangers with experimental validation, Appl. Therm. Eng., 65, 369-383, 2014.

[28] J. Liu, W. Liu, L. Ma, J. Yang, Thermal-hydraulic performance of a novel shell-and-tube oil cooler with multi-fields synergy analysis, Int. J. Heat Mass Transfer, 77, 928-939, 2014.

[29] M. Picon-Nunez, G.T. Polley, G. Martinez-Rodriguez, Graphical tool for the preliminary design of compact heat exchangers, Appl. Therm. Eng., 61, 36-43, 2013.

[30] B. V. Babu, S.A. Munawar, Differential evolution strategies for optimal design of shell-and-tube heat exchangers, Chem. Eng. Sci., 62, 3720-3739, 2007.

[31] M. Fesanghary, E. Damangir, I. Soleimani, Design optimization of shell and tube heat exchangers using global sensitivity analysis and harmony search algorithm, Appl. Therm. Eng. 29, 1026-1031, 2009.

[32] J. M. Ponce- Ortega, M. Serna-Gonzalez, A. Jimenez-Gutierrez, Use of genetic algorithms for the optimal design of shell-and-tube heat exchangers, Appl. Therm. Eng., 29, 03-209, 2009.

[33] A. C. Caputo, P. M. Pelagagge, P. Salini, Heat exchanger design based on economic optimization, Appl. Therm. Eng. 28, 1151-1159, 2008.

[34] A. Hadidi, A. Nazari, Design and economic optimization of shell-and-tube heat exchangers using biogeography-based (BBO) algorithm, Appl. Therm. Eng., 51, 1263-1272, 2013.

[35] J. Yang, A.W. Fan, W. Liu, A.M Jacobi, Optimization of shell and tube heat exchangers conforming to TEMA standards with designs motivated by constructal theory, Energy Convers. Manage., 78, 468-476, 2014.

[36] Y. Özcelik, Exergetic optimization of shell and tube heat exchangers using a genetic based algorithm, Appl. Therm. Eng. 27, 1849-1856, 2007.

[37] J. F. Guo, L. Cheng, M. T. Xu, Optimization design of shell and tube heat exchanger by entropy generation minimization and genetic algorithm, Appl. Therm. Eng. 29, 2954-2960, 2009.

[38] S. Wang, J. Wen and Y. Li, An experimental investigation of heat transfer enhancement for a shell-and-tube heat exchanger, Appl. Therm. Eng., 29 (11-12), 2433-2438, 2009.

[39] R. Mukherjee, Effectively design of shell-and-tube heat exchangers, Chem. Eng. Prog., 94, 21-37, 1998.

[40] TEMA, Standards of the Tubular Exchanger Manufacturers Association, $9^{\text {th }}$ Ed. Tubular Exchanger Manufacturers Association, New York, 2007.

[41] R.K. Shah, D.P. Sekulic, Fundamentals of heat exchanger design, New Jersey, Wiley, USA, 2003.

[42] A. Bejan, Shape and structure, from engineering to nature, Cambridge, UK, Cambridge University Press, 2000.

[43] K.N. Ahmad, M.H. Bashir, M.M.A. Bhutta, N. Hayat, A.R. Khan, S. Khan, CFD applications in various heat exchangers design: A review, Appl. Therm. Eng., 32, 1-12, 2012.

[44] A. Jimenez and M. Serna, A compact formulation of the Bell-Delaware method for heat exchanger design and optimization, Chem. Eng. Res. Des., 83, 539-550, 2005. 